\title{
Pain in and Around the Eye: How Big is the Problem?
}

\author{
Balkrishna Bhattarai ${ }^{1}$, Badri Prasad Badhu ${ }^{2}$ \\ ${ }^{1}$ Professor of Anesthesiology and pain management expert \\ ${ }^{2}$ Professor of Ophthalmology, BP Koirala Institute of Health Sciences, Dharan, Nepal
}

Though pain in general is known to be the commonest presenting symptom in our clinical practice, it is often inadequately addressed. The pain in and around the eye is not an exception. Most of the pain cases in ophthalmic practice may seem to be quite straight forward for diagnosis and management but many may pose challenges that warrant a wider view and a different approach of management with a multidisciplinary involvement; and some cases may need further work-up.

Pain caused by common ocular and orbital pathologies and of the ocular adnexa, e.g., corneal lesions (foreign body, keratitis, recurrent erosion syndrome etc.), dry eyes, angle-closure glaucoma, inflammatory eyelid conditions, acute herpes zoster ophthalmicus and by systemic disease like hyperthyroidism, may be easily diagnosed with the help of history and ophthalmic examination and has a reasonably clear line of management.

Intermittent angle-closure and anterior uveitis patients give a history of intermittent pain. Patients with Posner-Schlossman syndrome presenting with eye pain may have normal eye features except for a very high intraocular pressure.

Patients with uncorrected (or residual) refractive error, latent strabismus, or impairment of accommodation/convergence may have peribulbar and frontal pain which increases in intensity towards the evening, with other associated features that may include eye fatigue, blurring of vision and burning sensation (Bianchi-Marzoli \& Criscuoli, 2015).

The pain in and around the eye is often complained of as a headache. However, the treating physicians usually overestimate its importance (The International Headache Society, 1953). The criteria for classification of headache include an entity of headache associated with refractive error (HARE). Aknici et al (2008) have concluded that compound and mixed types of astigmatism, anisometropia and poorly-corrected refractive errors are frequently associated with headache.

Giant cell arteritis is an inflammatory condition that can cause eye pain (Hayreh, et al, 1998). The pain most likely results from cilio-retinal artery occlusion (Chacko \& Salter, 2015). This has been found to be more common in people of African origin (Garitty et al, 2017)). Elderly patients are mostly affected. The ESR and C-reactive protein are raised in the condition. And this arteritis responds to oral steroids (Rahman \& Rahman, 2005).

Pituitary apoplexy in a patient with pituitary adenoma can present initially with headache and pain around the eye with subsequent classic vision defects. The postulated mechanisms underlying the headache and pain around the eye include meningeal 
irritation, dura-mater compression, enlargement of sellar walls, or involvement of the superior division of the trigeminal nerve inside the cavernous sinus (Stephenson, 2010; Semple, 2007).

Eye pain can frequently be a part of orofacial pain syndromes. The eye, face, and most of the head is innervated by the trigeminal nerve. So patients with trigeminal nerve involvement can present with severe eye pain without remarkable ophthalmic findings (Maarbjerg et al, 2017; O'Neill, Nurmikko \& Sommer, 2017). Unfortunately, the condition is relatively common and often takes quite some time before the diagnosis is made. The pain can be severe enough to disrupt routine activities of the patient. Early suspicion of the condition and proper evaluation may reduce the suffering. Since the ophthalmic division of the trigeminal nerve also provides sensation to the cranial cavity including the dural blood vessels and the meninges, patients with intracranial pathologies can complain of pain in the eyes. Furthermore, patients with occipital neuralgia (involving greater occipital nerve) and cervical pathologies may also present with pain around the eyes. Anatomically, the pain fibers from the ocular region transmit signals via the ophthalmic branch of the trigeminal nerve to the sub-nucleus caudalis and ipsilateral upper cervical spinal cord $(\mathrm{C} 1-\mathrm{C} 2)$. The convergence of any pain mediated by nociceptive fibers from the afferent occipital/cervical cord (C1-C2) to the same region may explain the anatomical basis of the ipsilateral ocular referred pain (Kemp et al, 2011; Piovesan, 2003).

A case of corneal pain suggestive of a dry eye but with no clinical signs has been reported (Rosenthal, 2009). Such conditions are perhaps being under diagnosed.

Patients with post herpetic neuralgia may present with a disproportionately severe pain in and around the eye but may have no clear-cut ophthalmic findings. Patients with nasopharyngeal carcinoma may also initially present with eye pain and optic neuritis (Tsai, 2002) or with features of ophthalmic trigeminal neuralgia (The Royal Society of Medicine, 1953).

Certain headache syndromes can also be the cause of pain in and around the eyes. Though the typical description of the symptoms may guide the clinician to diagnosing the conditions, the pain, at times, may remain unexplained. Such syndromes are migraine, cluster headache and tension headache (Stephenson, 2010; Shephard et al, 2014).

It is estimated that approximately one-fifth of women and one-tenth of men suffer from migraine of one or other type (Manzoni, 2003). In addition to throbbing pain in the eye or orbit, migraine patients may have nausea and are light and sound sensitive. Some patients may report aura with normal ocular findings, whereas some others, particularly those with ocular migraine, may present with positive ophthalmic findings.

Cluster headache has male preponderance and the pain may be in the eye. The pain can be unbearable and be associated with lacrimation, nasal stuffiness, rhinorrhea, eyelid edema, conjunctival injection and features simulating Horner's syndrome during the attacks (Leroux, 2008).

Chronic paroxysmal hemicrania also resembles cluster headache, causing pain in and 
around the eye, but occurs in paroxysms of an hour or less, several times a day, and occasionally persists for years. Indomethacin is reportedly effective in its treatment (Osman, 2018).

The tension headache is the most common primary headache disorder in the general population. Though both peripheral and central mechanisms are believed to be involved, its pathophysiology remains unclear. Interaction between the limbic system, the descending inhibitory system, and peripheral inputs, such as those coming from the intracranial vasculature and myofascial inputs, has been speculated to result in the tension headache (Rasmussen, 1993; Olesen, 1991).

The neuralgiform headache occurs less commonly and with shorter episodes but attacks occur with conjunctival injection and tearing. This rare condition affects mostly the men and lasts for seconds, and it can occur hundreds of times a day (Levy, 2018).

Trochleitis is a condition characterized by localized swelling, tenderness and severe pain superomedially to the eye and is associated with triggering or accentuating migraine headaches (Yanguela et al., 2002).

Eye pain due to intra-orbital causes can be differentiated by the feature that the pain worsens on eye movement. Patients with early optic neuritis prior to vision loss may present with eye pain. Corneal neuropathy manifesting with pain in the eye mimicking dry-eye syndrome but with no clinical signs have been reported following LASIK surgery for high myopia. Abnormal re-growth of corneal nerves has been implicated for this eye pain (Tuisku, 2007).

Recent neurophysiological advances explain that many cases of dry eye syndrome may actually be representing some neuropathic pain syndromes and not attributable to the tear status. These syndromes may not be addressed by simple and single cure strategies; they require more intense assessment and collaboration with other specialties (Clayton, 2018; Jacob, 2017). Furthermore, many patients may have persistent pain following surgery of neuropathic nature described as complex regional pain syndrome. Complex pain syndromes require a multimodal approach involving local and systemic strategies.

It may be difficult to diagnose isolated ocular pain but most such cases are reasonably easy to treat. Patients suffering from pain in and around the eye can immensely benefit from our better understanding of these pain syndromes and from our collaboration with neurophysiologists and pain physicians.

\section{References}

Akinci A, Guven A, Degerliyurt A, Kibar E, Mutlu M, Citric M (2008). The correlation between headache and refractive errors. JAAPOS; 12(3):290-3.

Bianchi-Marzoli S \& Criscuoli A (2015). Headache attributed to visual disturbance. Neurol Sci; 36(Suppl. 1): s85-s88.

Chacko JG, Chacko JA \& Salter MW (2015). Review of giant cell arteritis. Saudi Journal of Ophthalmology; 29: 48-52. 
Choi I \& Jeon SR (2016). Neuralgias of the Head: Occipital Neuralgia. J Kor Med Sci; 31(4): 479-88.

Clayton JA (2018). Dry eye. N Engl J Med; 378: 2212-23.

Evers S (2017). Facial pain: Overlapping syndromes. Cephalalgia; 37(7): 705713.

Garrity ST, Pistilli M, Vaphiades MS et al. (2017). Ophthalmic presentation of giant cell arteritis in African-Americans. Eye (Lond); 31(1):113-118.

Hayreh SS, Podhajsky PA, Zimmerman B (1998). Ocular manifestations of giant cell arteritis. Am J Ophthalmol; 125(4):509-520.

Jacob DS (2017). Diagnosis and treatment of ocular pain; the ophthalmologists' perspective. Curr Ophthalmol Rep; 5: 271-275.

Kemp WJ, Tubbs RS \& Cohen-Gadol AA (2011). The innervation of the scalp: a comprehensive review including anatomy, pathology and neurosurgical correlates. Surg Neurol Int; 2: 178.

Leroux E \& Ducros A (2008). Cluster headache. Orphanet J Rare Dis; 3: 20. doi:10.1186/1750-1172-3-20.

Levy A \& Matharu MS (2018). Short-lasting unilateral neuralgiform headache attacks. Ann Indian Acad Neurol; 21(Suppl 1): S31-S38.

Maarbjerg S, Stefano GD, Bendtsen L \& Cruccu G (2017). Trigeminal neuralgia - diagnosis and treatment. Cephalalgia; 37(7): 648-657.

Manzoni GC \& Torelli P (2003). Epidemiology of migraine. J Headache Pain; 4(Suppl 1): s18-s22.

O’Neill F, Nurmikko T \& Sommer C (2017). Other facial neuralgias. Cephalalgia; 37(7): 658-669.

Olesen J (1991). Clinical and pathophysiological observations in migraine and tension-type headache explained by integration of vascular, supraspinal and myofascial inputs. Pain; 46(2): 125-132.

Osman C \& Bahra A (2018). Paroxysmal Hemicrania. Ann Indian Acad Neurol; 21(Suppl 1): S16-S22.

Piovesan EJ, Kowacs PA \& Oshinsky ML (2003). Convergence of cervical and trigeminal sensory afferents. Curr Pain Headache Rep.; 7(5): 377-383.

Rahman W \& Rahman FZ (2005). Giant cell (temporal) arteritis: an overview and update. Surv Ophthalmol.; 50(5): 415-28.

Rasmussen BK (1993). Migraine and tension-type headache in a general population: precipitating factors, female hormones, sleep pattern and relation to lifestyle. Pain; 53(1): 65-72.

Rosenthal P, Baran I \& Jacobs DS (2009). Corneal pain without stain: Is it real? Ocul Surf; 7(1): 28-40. 
Semple PL, Jane JA Jr, Laws ER Jr (2007). Clinical relevance of precipitating factors in pituitary apoplexy. Neurosurgery; 61: 956-61.

Shephard MK, MacGregor A, Zakrzewska JM (2014). Orofacial pain: a guide for the headache physician. Headache; 54: 22-39.

Stephenson M (2010). An anatomic approach to unexplained ocular pain. Review of Ophthalmology. Accessed on 10.10.2018 from www.reviewofophthalmology.com/ article/an-anatomic-approach-to-unexplained-ocular-pain

The Royal Society of Medicine (1953). Proceedings of the Royal Society of Medicine; 46: 817-824.

Tsai CC, Ho HC, Kau HC, Kao SC \& Hsu WM. (2002). Optic neuritis: a rare manifestation of nasopharyngeal carcinoma. Eye; 16: 501-503.

Tuisku IS, Lindbohm N, Wilson SE \& Tervo TM (2007). Dry eye and corneal sensitivity after high myopic LASIK. J Refract Surg.; 23(4): 338-342.

Yanguela J, Pareja JA, Lopez N, et al (2002). Trochleitis and migraine headache. Neurology; 58:802-805. 